\title{
EDUCAÇÃO DO CAMPO E SAÚDE: ANÁLISE DE MATERIAIS DIDÁTICOS PRODUZIDOS PELO SETOR SAÚDE DO MOVIMENTO SEM TERRA
}

\author{
Cibele Lima dos Santos (iD)1 Polyana Aparecida Valente (iD2 Denise Nacif \\ Pimenta (iD 3
}

Resumo: No ano de 1984, o Movimento dos Trabalhadores Rurais Sem Terra (MST), inaugurou oficialmente uma nova etapa sobre a luta pela terra no Brasil, colocando a Reforma Agrária como parte da construção de uma sociedade mais justa e igualitária. Ao longo de sua existência, várias páginas contornaram sua história, tendo a educação e a saúde como pautas desde sua formação. O Setor de Saúde se confirma como segmento dentro do Movimento no ano de 1998, com o intento de organizar as lutas pela saúde a partir de ações educativas, informativas e formativas. Assim, este artigo tem por objetivo analisar os materiais de saúde produzidos pelo Setor Nacional de Saúde do MST e do Setor Regional de Minas Gerais, destacando a relevância da Educação do Campo no processo de amadurecimento das produções didáticas inseridas no contexto da vida camponesa. Foram analisados seis materiais didáticos, entre cadernos e cartilhas de saúde, a partir das categorias: estrutura e formatação, conteúdo, linguagem, ilustrações e gênero. Almejou-se analisar como o MST aborda as questões de saúde em suas produções didáticas. Verificou-se que tais materiais constituem uma forma eficiente de diálogo que respeita a especificidades, tais como cultura, subjetividade e contexto social dos(as) assentados(as) e acampados(as). Observou-se, também, por meio de pesquisa exploratória, uma ausência de trabalhos que analisam tais produções, tornando-se este relevante para os movimentos sociais. Conclui-se que os materiais produzidos são instrumentos importantes para a produção de conhecimento, informação e formação dentro e fora dos espaços educacionais da população do campo, demonstrando o potencial do movimento ao construir e lutar por uma saúde ampla, inclusiva e não opressora.

Palavras-chave: Luta pela terra; Setor saúde; Materiais educativos; Educação popular.

\section{RURAL EDUCATION AND HEALTH: ANALYSIS OF EDUACTIONAL MATERIALS PRODUCED BY THE HEALTH CARE SECTOR OF LANDLESS WORKERS MOVEMENTS}

\footnotetext{
${ }^{1}$ Mestra em Ensino em Saúde pela Universidade Federal dos Vales do Jequitinhonha e Mucuri (UFVJM). Doutoranda em Saúde Coletiva pelo Instituto Renê Rachou - Fundação Oswaldo Cruz (FIOCRUZ- MINAS) - Ministério da Saúde. E-mail: limabelsantos@gmail.com.

${ }^{2}$ Doutora em História pela Universidade Federal de Minas Gerais (UFMG). Professora da Universidade Estadual de Minas Gerais (UEMG). E-mail: polyvalente84@gmail.com.

${ }^{3}$ Doutora em Ciências da Saúde Pública pelo Instituto Renê Rachou - Fundação Oswaldo Cruz (FIOCRUZ- MINAS) - Ministério da Saúde, pesquisadora da Fundação Oswaldo Cruz. E-mail: denise.pimenta@fiocruz.br.
} 
Abstract: In 1984, the Landless Workers Movement (Movimento dos Trabalhadores Rurais Sem Terra, or MST) officially initiated a new stage of land dispute in Brazil, placing agrarian reform as part of a more just and equal society construction. Since its formation and throughout its existence, education and health care were the MST's fighting guidelines, whilst several others also crossed its history. The Health Care Sector configured itself as a segment within the movement in 1998. It targeted the organization of the fight for health care rights via educational, informative, and training practices. Thus, this article aims to analyze the health educational materials produced by MST's National Health Care Sector, as well as Minas Gerais regional branch, highlighting the relevance of Rural Education in the maturing process of the didactic productions inserted in the peasant's life context. In order to verify how MST addresses health issues in its literary production, six educational materials were examined. Among leaflets and booklets, these were analyzed based on the following categories: structure and formatting, content, language, illustrations, and genre. It was found that those materials establish an efficient dialogue format, which respects particularities of the peasant's life contexts., such as culture, subjectivity, and social context. A lack of research on such educational materials was also noticed, underlining the relevance of this work for social movements. We conclude that the materials are important instruments for the knowledge production, information, and training within and outside the educational spaces of the rural population. Thereby, it demonstrates the MST's potential to build and fight for a broad, inclusive, and non-oppressive health care.

Keywords: Fight for land; Health care sector; Educational materials; Popular education.

\section{Introdução}

A questão dos conflitos pela terra permeia toda a história do Brasil, tendo como marco inaugural os anos 1500, momento em que os portugueses invadiram as terras brasileiras, vislumbrando as riquezas naturais e humanas e desconsiderando a presença de indígenas que já se encontravam estabelecidos no território. De lá para cá, são inúmeras lutas, estratégias de resistência e ocupação, das quais destacamos a Lei de Terras (1850), o Contestado (18961897), a revolta de Canudos (1934-1938) e o recente Movimento de Luta Pela Terra e seu violento massacre de Eldorado, em 1996, cuja tragédia completou 25 anos em abril de 2021. Tais conflitos surgem da necessidade da partilha da terra que, historicamente, se concentra nas mãos de uma pequena classe oligárquica dominante.

Desse histórico de lutas, o Movimento dos Trabalhadores Rurais Sem Terra (MST) emerge em 1984, em um contexto de efervescência política e social, que apontava para a redemocratização do país. Assim, no presente trabalho, utilizamos as lutas no plural, porque compreendemos que lutar pela terra inclui uma amplitude de direitos muitas vezes negados à população residente no campo. Nesse sentido, a luta por saúde é uma das pautas priorizadas pelo Movimento, pois, ao longo dos anos, o MST constrói e lapida um conceito de 
saúde que se desdobra junto aos preceitos do Movimento, pelos quais "lutar por saúde é lutar contra tudo que os oprime" (ESP, 2018, p. 9).

O Setor de Saúde está presente no MST desde as primeiras ocupações, tendo como protagonistas do cuidado os(as) próprios(as) acampados(as). No ano de 1998, com objetivo de priorizar a luta pela saúde no interior do Movimento, a partir de uma frente nacional, o Setor de Saúde consolidou ações e diálogos, afirmando como valores da saúde os seguintes pontos:

a luta pela valorização da vida; a saúde como conquista de luta popular; saúde como direito; saúde como luta de consolidação de políticas públicas; respeito às diferenças; fortalecimento das práticas e saberes populares em saúde; educação permanente em saúde e socialização dos conhecimentos e informações adquiridas nos processos de formação. (MST, 2007, p. 4).

Desde então, várias ações começaram a dar vida ao Setor, dentre as quais destacamos a produção de materiais didáticos, oficinas de cuidado baseado em produtos naturais, conscientização dos(as) assentados(as) e acampados(as) acerca do direito ao Sistema Único de Saúde (SUS), além de discussões sobre alimentação saudável.

Na esteira da conscientização sobre os valores de saúde do MST, observase uma forte influência do referencial teórico da Educação Popular e da Educação Popular em Saúde, acompanhando a proposta de um novo olhar para a vida do cidadão camponês, porque

a educação passa a ser considerada um instrumento para que as classes subalternas lutem para ocupar um lugar na sociedade, onde até então Ihes havia sido negado. Freire (1987) afirma que a liberdade é uma conquista que exige busca incessante e permanente, desse modo, a independência precisa ser forjada com o homem e não para ele, de forma que faça da opressão e de suas causas como objetos de reflexão dos oprimidos. $\mathrm{O}$ autor acredita que a responsabilidade de embater essa luta é condição fundamental para o engajamento necessário na luta pela libertação, vislumbrando, assim, uma possibilidade de transformação social (STÊNICO; PAES, 2017, p. 51).

A Educação Popular desponta como uma corrente vigorosa nos idos de 1940, centrada na educação de base que se constitui como "processo [educativo] destinado a proporcionar a cada indivíduo os instrumentos indispensáveis ao domínio da cultura de seu tempo, as técnicas que facilitassem o acesso a essa cultura" (CORSO; ALMEIDA, 2015, p. 1286).

Destarte, tal definição acompanhava a forma hegemônica de ensino, cujo objetivo era a transferência de conteúdo para formação de mão de obra a fim de suprir as necessidades do mercado (BRASIL, 2014), desconsiderando a pluralidade da população brasileira e as subjetividades do homem. Na década de 1950, a perspectiva de uma educação mais inclusiva e crítica ressoa no meio educacional, trazendo para o debate a Educação de Jovens e Adultos (EJA), sendo esse o marco de uma Educação Popular que valoriza as especificidades da formação humana heterogênea observada no país. De 1950 até os dias de hoje, entre uma ditadura militar agressiva e cerceadora de direitos e uma democracia 
incipiente, a Educação Popular, ainda que de forma restrita, aponta para seus sinais de resistência. Entretanto, é no século $X X$ que ela se fortalece enquanto ideal de uma educação em movimento, visto que

o período de resistência à ditadura e da redemocratização das décadas de 1970 e 1980 foi marcado pelo fortalecimento dos movimentos de educação e da Educação Popular como instrumento de organização dos movimentos populares. A perspectiva da educação pública e gratuita via Estado é fortalecida, ao mesmo tempo em que se extrapola o campo das políticas de educação. Principalmente na década de 1980 , os processos de organização social e popular representaram expressivas experiências de formação de consciência coletiva potencializadora da luta por direitos e reformas sociopolíticas, como no movimento sindical urbano, movimento estudantil, movimentos populares, Movimento Popular de Saúde, Movimento Nacional de Meninos e Meninas de Rua, Movimento dos Trabalhadores Rurais Sem Terra, Conselho Indigenista Missionário, Pastoral da Terra etc. (BRASIL, 2014, p. 33).

Ao longo do século XX, a Educação Popular, que "a um só tempo é uma concepção prático-teórico e uma metodologia de educação que articula os diferentes saberes e práticas , as dimensões da cultura e dos direitos humanos" (BRASIL, 2014, p. 7), passa a ser amplamente trabalhada nas bases comunitárias e nos movimentos sociais, estabelecendo-se como modelo educacional pautado pela emancipação do homem, na ação transformadora de realidades e no esperançar, conceito amplamente difundido na teoria de Paulo Freire.

Aliada à Educação Popular, a Educação Popular em Saúde sincroniza a necessidade de se fazer uma saúde diferente, "historicamente marcada pela centralidade na transmissão de informações e mudança de comportamentos" (PARO; VENTURA; SILVA, 2020, p. 2). Nesse sentido, a Educação Popular em Saúde busca ressignificar a saúde de modo que essa se torne uma cultura em relação com as classes populares, representando uma ruptura com a tradição autoritária e normatizadora da Educação em Saúde (VASCONCELOS, 2004).

Na mesma direção, é necessário destacar que as Políticas Públicas voltadas para a Educação no Campo, como o Programa Nacional de Educação no Campo (PRONACAMPO), instituído pelo Decreto no 7.352 e chancelado pela Portaria 86/2013, tornam-se instrumentos para construção de uma Educação no Campo que se constitui de um "conjunto de ações voltadas ao acesso e a permanência na escola, à aprendizagem e à valorização do universo cultural das populações do campo" (BRASIL, 2013, p. 3).

Desse modo, pensando a trajetória do MST na construção de uma educação crítica e de uma saúde não mercantilizada, este artigo tem por objetivo analisar os Cadernos Nacionais de Saúde produzidos, nos anos de 1999 e 2000, pela equipe do Setor de Saúde da organização nacional, bem como dois materiais de saúde produzidos pelo Setor Regional do Movimento, em Minas Gerais, e que dialogam com as produções nacionais. A inclusão dos Cadernos Regionais, produzidos nos anos de 2014 e 2018, visa acompanhar o amadurecimento teórico e informativo que o Setor de Saúde acumulou, refletidos nas produções locais dos acampamentos e assentamentos do Brasil. Aliado a isso, optamos por analisar o material de Minas Gerais, uma vez que a 
atual pesquisa desenvolvida pelas proponentes do artigo se dá em torno da memória, da saúde popular e das mulheres do MST atuantes no Vale do Rio Doce (MG). Como dito anteriormente, tais materiais foram construídos com foco na formação dos companheiros e companheiras da luta pela terra, sob intuito de informar sobre os mecanismos de saúde constantes na Constituição, além de propor tecnologias sociais para desenvolvimento de uma saúde que dialogue e vá de encontro à realidade do campo.

\section{Metodologia}

A busca pelo material foi realizada tanto no site do MST (www.mst.org.br), quanto em formato impresso. Foram registradas cinco produções nacionais, sendo que o caderno no 3 não foi encontrado nos formatos pesquisados; além de um caderno e uma cartilha produzidos regionalmente, totalizando seis materiais a serem analisados, assim distribuídos:

- Caderno n. ${ }^{\circ} 1$ - Lutar por saúde é lutar pela vida (1999a);

- Caderno n. 02 - Programa Terra e saúde (1999b);

- Caderno n.o 4 - Cultivo de Plantas Medicinais (2000a);

- Caderno n. 5 - Construindo o Conceito de Saúde no MST (2000b);

- Cuidados em Saúde Mental - Diálogos entre o MST e o SUS (2014);

- Mulheres, Agroecologia e as Lutas por Saúde: 30 anos do SUS, 20 anos do Setor de Saúde do MST - MG (2018).

A análise dos materiais selecionados se justifica pelo interesse em verificar como o MST aborda a questão da saúde com os(as) assentados(as) e acampados(as), delimitando categorias de análise conforme os tópicos a seguir.

\subsection{Critérios e procedimentos de análise}

Os critérios para efetuar as análises partiram, primeiramente, da ação de separar os materiais por temas em comum. As análises foram realizadas em três agrupamentos:

1. Análise conjunta dos cadernos: n. ${ }^{\circ} 1$ - Lutar por saúde é lutar pela vida e n. ${ }^{\circ} 5$ - Construindo o conceito de saúde no MST, em que foram abordados os temas do SUS e o conceito de saúde. 2. Análise conjunta dos cadernos: n. ${ }^{\circ} 2$ - Programa Terra e Saúde e n. ${ }^{\circ} 4$ - Cultivo de plantas medicinais, onde foram consideradas as discussões sobre o conceito e a produção de medicamentos fitoterápicos. 3. Análise dos cadernos regionais MG: Cuidados em Saúde Mental - Diálogos entre o MST e o SUS e Mulheres, Agroecologia e Lutas por Saúde: 30 anos de SUS, 20 anos do Setor de Saúde do MST - MG.

Para as análises, foram utilizados parâmetros de acordo com a metodologia adaptada a partir de Assis, Pimenta e Schall (2013) - que, por sua vez, baseiam-se nas propostas de Mohr (2000), Luz et al. (2003), Vasconcelos e Souto (2003) Santos et al. (2007), Almeida, Silva e Brito (2008), Ferreira e Soares (2008) e Batista, Cunha e Cândido (2010). Considerando, para tanto, estrutura, conteúdo, linguagem e ilustrações. A fim de compreender as percepções de gênero nos materiais analisados, essa categoria foi incluída, 
adaptando o modelo citado, pois discutir gênero no interior de um movimento rural, em que as mulheres são frequentemente silenciadas, torna-se um ponto a mais para verificar sua existência no meio. O Quadro 1 resume as categorias analisadas:

\section{Quadro 1 - Categorias e tópicos de análise.}

\begin{tabular}{|c|c|}
\hline Categorias & Tópicos \\
\hline 1. Estrutura e formatação & $\begin{array}{l}\text { (a) tamanho do texto (número de } \\
\text { páginas); (b) indicação de outros } \\
\text { autores ou colaboradores;(c) localização } \\
\text { do texto no exemplar (texto, exercícios, } \\
\text { texto complementar, anexos e outros } \\
\text { aspectos); (d) tamanho da fonte (se é } \\
\text { favorável à leitura) }\end{array}$ \\
\hline 2. Conteúdo & $\begin{array}{c}\text { (a) necessidade de pré-requisito para } \\
\text { compreensão;(b) correção científica;(c) } \\
\text { adequação ao público-alvo; (d) } \\
\text { contextualização em relação ao público- } \\
\text { alvo; (f) falta/excesso de definições;(g) } \\
\text { referências bibliográficas e adequações } \\
\text { dos conceitos; (h) tópicos abordados; } \\
\text { (h) contextualização do tema ao público- } \\
\text { alvo. }\end{array}$ \\
\hline 3. Linguagem & $\begin{array}{l}\text { (a) Clareza e objetividade; (b) } \\
\text { linguagem compreensível e adequada; } \\
\text { (c) presença de ideias preconceituosas, } \\
\text { estereotipadas e ideológicas. }\end{array}$ \\
\hline 4. Ilustrações & $\begin{array}{l}\text { (a) pertinência ou redundância em } \\
\text { relação ao texto; (b) presença de } \\
\text { autoria;(c) apresentação atraente e } \\
\text { organizada; (d) qualidade e quantidade } \\
\text { pertinente; (e) Legenda }\end{array}$ \\
\hline 5. Gênero & $\begin{array}{l}\text { (a) Inclusão da discussão de gênero; (b) } \\
\text { tratamento da questão nas ilustrações; } \\
\text { (c) autoria; }\end{array}$ \\
\hline
\end{tabular}

Fonte: Adaptado de Assis, Pimenta e Schall (2013).

Já os Quadros 2, 3 e 4, listam detalhes editoriais das publicações analisadas:

Quadro 2 - Cadernos de Saúde n.o 1 e n. 5.

\begin{tabular}{|c|c|c|c|c|c|}
\hline Caderno & Autoria & $\begin{array}{c}\text { Título do } \\
\text { Material }\end{array}$ & Público & $\begin{array}{c}\text { Editora } \\
\text { Cidade }\end{array}$ & Ano \\
\hline 1 & $\begin{array}{c}\text { Coletivo } \\
\text { Nacional de } \\
\text { Saúde MST }\end{array}$ & $\begin{array}{c}\text { Lutar por saúde } \\
\text { é lutar pela vida }\end{array}$ & $\begin{array}{c}\text { Assentadas(os) } \\
\text { Acampados(as) } \\
\text { MST }\end{array}$ & $\begin{array}{c}\text { Gráfica e } \\
\text { Editora } \\
\text { Peres } \\
\text { São Paulo }\end{array}$ & 1999 \\
\hline 5 & $\begin{array}{c}\text { Setor } \\
\text { Nacional de } \\
\text { Saúde MST }\end{array}$ & $\begin{array}{c}\text { Construindo o } \\
\text { conceito de } \\
\text { saúde no MST }\end{array}$ & $\begin{array}{c}\text { Assentadas(os) } \\
\text { Acampados(as) } \\
\text { MST }\end{array}$ & $\begin{array}{c}\text { Gráfica } \\
\text { GH São } \\
\text { Paulo }\end{array}$ & 2000 \\
\hline
\end{tabular}

Fonte: Adaptado de Brasil (apud ASSIS; PIMENTA; SCHALL, 2013). 


\begin{tabular}{|c|c|c|c|c|c|}
\multicolumn{9}{c}{ Quadro 3 - Cadernos de Saúde n.o 2 e n.o 4. } \\
\hline Caderno & Autoria & $\begin{array}{c}\text { Título do } \\
\text { Material }\end{array}$ & Público & $\begin{array}{c}\text { Editora } \\
\text { Cidade }\end{array}$ & Ano \\
\hline 2 & $\begin{array}{c}\text { Setor } \\
\text { Nacional } \\
\text { de Saúde } \\
\text { MST }\end{array}$ & $\begin{array}{c}\text { Programa } \\
\text { Terra e Saúde } \\
- \text { Das Plantas } \\
\text { construindo } \\
\text { uma nova } \\
\text { saúde }\end{array}$ & $\begin{array}{c}\text { Assentados(as) } \\
\text { Acampados(as) } \\
\text { MST }\end{array}$ & $\begin{array}{c}\text { Gráfica e } \\
\text { Editora Peres } \\
\text { São Paulo }\end{array}$ & 1999 \\
\hline 4 & $\begin{array}{c}\text { Setor } \\
\text { Nacional } \\
\text { de Saúde } \\
\text { MSTe } \\
\text { CONCRAB }\end{array}$ & $\begin{array}{c}\text { Cultivo de } \\
\text { Plantas } \\
\text { Medicinais - } \\
\text { Programa } \\
\text { Terra e Saúde }\end{array}$ & $\begin{array}{c}\text { Assentados(as) } \\
\text { Acampados(as) } \\
\text { MST }\end{array}$ & - & 2000 \\
\end{tabular}

Fonte: Adaptado de Brasil (apud ASSIS; PIMENTA; SCHALL, 2013).

Quadro 4 - Material Educativo Regional.

\begin{tabular}{|c|c|c|c|c|c|}
\hline Gênero & Autoria & $\begin{array}{l}\text { Título do } \\
\text { Material }\end{array}$ & Público & $\begin{array}{l}\text { Editora } \\
\text { Cidade }\end{array}$ & Ano \\
\hline Caderno & $\begin{array}{l}\text { Coletivo de } \\
\text { Saúde MST } \\
\text { - Vale do } \\
\text { Rio Doce } \\
\text { (MG) / } \\
\text { Escola de } \\
\text { Saúde } \\
\text { Pública MG }\end{array}$ & $\begin{array}{l}\text { Cuidados em } \\
\text { Saúde Mental } \\
\text { - Diálogos } \\
\text { entre o MST e } \\
\text { o SUS }\end{array}$ & $\begin{array}{c}\text { Assentados(as) } \\
\text { Acampados(as) } \\
\text { MST Minas } \\
\text { Gerais }\end{array}$ & $\begin{array}{c}\text { Imprensa } \\
\text { Oficial de } \\
\text { Minas Gerais }\end{array}$ & 2014 \\
\hline Cartilha & $\begin{array}{l}\text { Coletivo de } \\
\text { Saúde MST } \\
\text { - MG) / } \\
\text { Escola de } \\
\text { Saúde } \\
\text { Pública MG }\end{array}$ & $\begin{array}{c}\text { Mulheres, } \\
\text { Agroecologia } \\
\text { e as Lutas por } \\
\text { Saúde - } 30 \\
\text { anos do SUS, } \\
20 \text { anos do } \\
\text { Setor de } \\
\text { Saúde do } \\
\text { MST-MG }\end{array}$ & $\begin{array}{c}\text { Assentados(as) } \\
\text { Acampados(as) } \\
\text { MST Minas } \\
\text { Gerais e público } \\
\text { afim. }\end{array}$ & $\begin{array}{l}\text { Parque Gráfico } \\
\text { da Cia de } \\
\text { Tecnologia da } \\
\text { Informação do } \\
\text { Estado de MG } \\
\text { - Prodemge }\end{array}$ & 2018 \\
\hline
\end{tabular}

Fonte: Adaptado de Brasil (apud ASSIS; PIMENTA; SCHALL, 2013).

\section{Resultados e discussões}

\subsection{Estrutura e formatação}

As primeiras produções didáticas de cunho nacional do Setor de Saúde datam do ano de 1999, momento em que foi construído coletivamente o primeiro Caderno de Saúde do Movimento. Sob o título Lutar por saúde é lutar pela vida, o material tem por objetivo levar ao conhecimento dos acampados e assentados a ideia de direitos à saúde e a sua garantia na Constituição, como informa o preâmbulo:

Como primeira discussão, este material traz elementos para que possamos entender quais as formas de garantir nosso direito de assistência à saúde. E trata das conquistas já garantidas na lei, mas que ainda não estão garantidas na prática. Cabe a nós, junto com as outras 
organizações, lutarmos para garantir o que é direito do povo: um atendimento à decente saúde, com qualidade, onde a vida humana tenha valor (MST, 1999a, p. 3).

O segundo material, produzido pelo setor no mesmo ano de 1999, ressalta a importância do cultivo de plantas medicinais em seu potencial tratativo, além de mencionar a valorização dos saberes populares, dialogando com as tradições ancestrais e geracionais. O Programa Terra e Saúde - das plantas construindo uma nova saúde chega ao Movimento por meio de parceria com a Fundação Oswaldo Cruz (FIOCRUZ), com objetivo de potencializar a fabricação de remédios em uma perspectiva agrofarmacêutica. Trata-se de um Programa com raízes técnicas e sociais, que visa à produção de medicamentos fitoterápicos, desde o plantio, colheita, beneficiamento e distribuição dos medicamentos (MST, 1999b). Com controle de qualidade acompanhado de perto pela equipe da FIOCRUZ, através da Farmanguinhos - Instituto de Tecnologia em Fármacos, o programa beneficiou muitos assentados e as comunidades, no entorno dos assentamentos, espalhadas pelo território brasileiro. Tal programa demonstra a força do coletivo em franca produção e as inovações tecnológicas na saúde do campo, conforme se pode observar no trecho a seguir:

O Programa Terra e Saúde conta basicamente com um complexo agrofarmacêutico constituído de horta e laboratório. Tal complexo em pleno funcionamento tem capacidade de produzir medicamentos para atender 40 mil pessoas/ano. Ele contempla 3 estágios, sendo o primeiro de produção de ervas, um segundo de produção de produtos padronizados para o mercado (beneficiamento) e um terceiro que se refere à distribuição do produto final. (MST, 1999b, p. 8).

A fim de reafirmar a importância e a potencialidade do Programa, no ano 2000, em consonância com suas bases de formação, o Setor de Saúde lança o Caderno de Saúde n. ${ }^{4}$ 4. Sob o título Cultivo de Plantas Medicinais, o Caderno trata especificamente da parte técnica do Programa Terra e Saúde, orientando sobre "como instalar e organizar, em etapas, o horto de plantas medicinais, levando em consideração a necessidade de qualificação no aproveitamento das propriedades fitoterápicas das plantas a serem cultivadas" (MST, 2000a, p. 5).

Por fim, o Caderno n. ${ }^{\circ} 5$ (MST, 2000b) traz à luz o tema Construindo o conceito de saúde do MST, apresentado em um material amplamente ilustrado, com a finalidade de tornar-se um guia dialógico para as discussões sobre saúde, bem como sobre o SUS. O caderno se divide em três eixos, sendo o primeiro o que se entende por saúde, seguido por como construir novos hábitos, costumes e valores no cotidiano voltado para saúde e, por fim, o que é e como funciona o SUS.

É importante ressaltar que o material enfatiza que o conteúdo disponibilizado não trata de um passo a passo para sanar a questão da saúde da população rural, mas se constitui como um material de estudo crítico com fins de construção coletiva do conceito de saúde no interior do Movimento. Conforme ponderam os autores: 
o assunto, mas provocar o debate para que todos nós possamos construir novas relações e postura em torno da saúde e, também ampliar nosso saber sobre o tema. (MST, 2000b, p. 4).

Os Cadernos e a Cartilha apresentam ficha catalográfica (expediente), sumário e apresentação. Importa ressaltar que, na seção apresentação, apenas nos cadernos n. ${ }^{\circ} 1$ e 5, os termos companheiros/companheiras dão tom a quem o material é efetivamente dirigido, uma vez que tal expressão é saudação própria do MST.

O Caderno n. 04 apresenta saudação apenas aos companheiros e nos chama a atenção por sugerir ser um material dirigido ao público masculino, o que é confirmado ao acessarmos suas páginas. Há um pensamento machista simbolizado no ato de elaborar a construção e a estrutura dos hortos, bem como o pegar na enxada, preparar a terra para receber os insumos e dar vida ao projeto de produção de remédios fitoterápicos. Percebe-se, assim, um contrassenso, visto que a mulher ocupa um papel relevante na luta pela transformação da realidade machista e patriarcal instalada no Movimento. Essa percepção é corroborada a partir dos novos contornos do movimento feminista no Brasil, bem como pelo surgimento de vários movimentos de mulheres organizadas no campo. Ao longo das análises dos demais materiais (em especial dos Cadernos regionais), tornou-se nítido como as mulheres vieram desconstruindo a imagem de fragilidade e dominação, historicamente reforçada pelo patriarcado.

O quesito impressão gráfica é considerado de qualidade razoável para a produção nacional e muito bom para o material regional. O tamanho e a fonte tipográfica são pertinentes à leitura. No Caderno nacional no 5 e no regional, Cuidados em saúde mental, há perguntas para que o público dialogue com o material, possibilitando uma reflexão crítica sobre o conteúdo proposto. Tal prerrogativa vai de encontro aos preceitos da Educação do/no Campo e da Educação Popular, que perpassa a formação crítica, humana e política. Santos (2017) enfatiza que a produção de conhecimento nas escolas do campo pode

ressignificar memórias, identidades e histórias vividas pelos sujeitos que se articulam para superar a opressão e as diversas cercas do analfabetismo, da fome e a falta de projetos emancipadores para/com o homem e a mulher do campo. Essa formação política, contextualizada historicamente, pode contribuir na reconstrução do passado, escavando memórias e acontecimentos, recuperando documentos, fontes primárias e produzindo histórias críticas e contra-hegemônicas. A produção do saber construída em parceria com educadores, educandos e lideranças dos movimentos sociais pode ser ressignificada na luta por suas histórias de vida, valores e reconhecimento (SANTOS, 2017 p. 210).

Desse modo, pensar um material interativo e político-crítico, que desperte o interesse e promova a participação e formação da população do campo, mostra-se ideal para que esses sujeitos possam se sentir parte do processo de construção estruturante do país e de suas lutas. 
Os materiais desenvolvidos pelo Setor de Saúde trazem em suas composições um conteúdo de cunho informativo e formativo. Nota-se que em nenhum dos Cadernos há a necessidade de pré-requisitos para exploração das propostas pelos sujeitos do Movimento. Também não se observou um diálogo com a ciência hegemônica. Em breves passagens, a nomenclatura de plantas conhecidas popularmente foi associada a seu nome científico. A linguagem predominante é a do saber popular, uma vez que a intenção do material é a de falar do povo para o povo, construir com e não somente para. Não se pode descartar a presença de um discurso romantizado e político, traços marcantes na caminhada de movimentos sociais. Para o Movimento dos Trabalhadores Rurais Sem Terra, a arte, a literatura, a poesia, a música e a mística fazem parte do processo de resistência. Ressalta-se que informações incorretas sobre os conceitos e preceitos relacionados ao SUS, bem como os relacionados ao Programa Terra e Saúde, não foram observadas.

Sobre as referências bibliográficas utilizadas, o único material nacional em que aparecem é o Caderno n.0 4 - Cultivo de Plantas Medicinais. Nas produções de Minas Gerais, contudo, a presença de fontes consultadas e referenciadas é maciça. Para essa ação, presume-se que a ausência das referências perpassa o caráter popular e não-oficial do material, renunciando à linguagem acadêmica/científica, o que pode se constituir em uma falha, pois conceitos e colocações que dão vida ao material foram consultados em alguma fonte e são possuidoras de propriedade intelectual. Tal ação infringe uma regra da escrita literária, fundamental para identificação da autoria, fundamentação, credibilidade e consistência de um texto. Esse fato elucida como os diálogos entre saberes científicos e populares são fruto de tensões, distâncias, aproximações, muitas negociações e relações dicotômicas de poder.

Os tópicos abordados foram pertinentes ao proposto na apresentação dos Cadernos. Há presença de sumário, que foi desenvolvido em cada material. A título de exemplo, no tópico "Diferença entre a lei e a realidade", desenvolvido no Caderno n.0 1, a temática discutida perpassa a função que os Conselhos exercem na sociedade; entretanto, na prática, o que é instituído destoa do que é prescrito em lei. Vejamos:

\footnotetext{
Existem centenas de conselhos formados, mas na prática poucos funcionam de fato. Conhecemos vários problemas, como: prefeito controla o conselho, pois, é ele quem indica seus membros; desrespeito quanto a composição do conselho, onde, os representantes dos usuários são em menor número em relação aos outros setores; conselhos que só existem no papel (MST, 1999a, p. 10).
}

Desse modo, percebe-se que a divisão em tópicos se torna um elemento organizativo, a fim de facilitar o entendimento do leitor. Essa divisão demonstra que, a partir de um tema "guarda-chuva", vários outros compõem a temática central da proposta. Nesse caso, o Caderno Lutar por saúde é lutar pela vida se desdobra em vários subtemas capazes de alimentar a proposta do material. 


\section{Quadro 5 - Descrição resumida sumário por caderno nacional.}

\begin{tabular}{|c|c|}
\hline Caderno & Título de tópicos abordados \\
\hline 1 & O que é o SUS \\
\hline 1 & $\begin{array}{c}\text { Diferença entre a lei e a } \\
\text { realidade.... }\end{array}$ \\
\hline 2 & $\begin{array}{c}\text { Pensando a respeito da saúde } \\
\text { O Programa Terra e Saúde e os } \\
\text { assentamentos }\end{array}$ \\
\hline 2 & $\begin{array}{c}\text { Implantaça do Horto de Plantas } \\
\text { medicinais }\end{array}$ \\
\hline 4 & Cultivo das Plantas Medicinais \\
\hline 5 & Como Utilizar os materiais \\
\hline 5 & A Saúde no ambiente doméstico \\
\hline
\end{tabular}

Fonte: Autoria própria.

\section{Quadro 6 - Descrição resumida sumário por material regional.}

\begin{tabular}{|c|c|}
\hline Material & Título de tópicos abordados \\
\hline 2014 & A Saúde na Reforma Agrária \\
\hline 2014 & Saúde mental, álcool e drogas \\
\hline 2014 & As práticas populares de cuidado \\
\hline 2018 & O Setor Saúde do MST \\
\hline 2018 & $\begin{array}{c}\text { Ambiente, Saúde e Cuidado: } \\
\text { Diálogos entre o MST e o SUS }\end{array}$ \\
\hline
\end{tabular}

Fonte: Autoria própria.

\subsection{Linguagem}

Para analisar a linguagem empregada nos materiais, lançamos mão do referencial da Educação Popular, uma vez que tal metodologia tem sido a estratégia mais efetiva para comunicação e ação na esfera dos movimentos sociais, em especial nos movimentos que têm como ponto central a defesa da dignidade humana.

Conforme ponderado, a Educação Popular tem por objetivo

promover o diálogo para a construção da autonomia e emancipação dos grupos populacionais que historicamente foram excluídos em seu modo de entender a vida, em seus saberes e nas oportunidades de participar dos rumos da sociedade brasileira (BRASIL, 2007, s/p.).

Nesse sentido, os Cadernos analisados, por trabalharem na perspectiva metodológica da Educação Popular, fazem uso de uma linguagem acessível para que o público consiga se apropriar do conteúdo exposto. Dessa forma, ao levarem o conhecimento para o cotidiano, a partir da teoria, os resultados podem ser potencializados e transformados em ações efetivas.

Os Cadernos n. 01 e 5, bem como as produções regionais, ao abordarem a temática do SUS e o conceito de saúde em uma linguagem acessível, incentivam os militantes a se apoderarem dos conceitos e a lutarem por seus direitos. O Caderno n.o 5 ultrapassa os limites de apenas informar ao leitor/receptor, e propõe aos militantes atividades que os incitam a pensar sobre as proposições de uma forma reflexiva-critica, além de transformá-los em sujeitos participativos da vida política e social do país. 
Por sua vez, os Cadernos n. ${ }^{\circ} 2$ e 4 seguem uma linguagem técnica, já que tratam de um Programa de desenvolvimento de tecnologias sociais direcionadas ao público do Movimento e também externo a ele. Ressalta-se, contudo, que não se trata de uma linguagem difícil, que poderia impedir a comunicação com a população do Movimento.

Assim, considerando que o MST é um movimento que luta contra as amarras e diferenças sociais e que tem a discussão por direitos como tema central de sua caminhada, é inevitável a presença de expressões que reforcem a não dominação da classe trabalhadora, a fim de criar uma consciência social e política coletiva, que dê sentido à luta. Desse modo, se instala um embate contra ideologias hegemônicas que venham a diminuir e/ou enfraquecer os objetivos do Movimento. Ecoando Marilena Chauí, Figueiredo, Brito e Botazzo (2003) informam que

a luta de classes não é apenas o confronto armado, mas: está presente em todos os procedimentos institucionais, políticos, policiais, legais, ilegais de que a classe dominante lança mão para manter sua dominação, indo desde o modo de organizar o processo de trabalho e o modo de se apropriar dos produtos (pela exploração da mais-valia e pela exclusão dos trabalhadores do usufruto dos bens que produziram), até as normas do direito e o funcionamento do Estado. Ela está presente também em todas as ações dos trabalhadores para diminuir a dominação e a exploração, indo desde a luta pela diminuição da jornada de trabalho, o aumento de salário, greves, à criação de sindicatos livres e a formação de movimentos políticos (2003, p. 757).

Destarte, expressões e orações contidas nos Cadernos e Cartilha analisados, como "equidade significa tratar de forma diferente os desiguais" (MST, 1999a, p. 7), ou: "Os principais inimigos são as empresas de saúde que lucram com a doença da população e o governo neoliberal que quer transformar nossas vidas em mercadorias" (MST, 1999a, p. 10), dentre outras, reforçam a necessidade do comprometimento da militância, tendo em mente que "é impossível compreender a origem e a função da ideologia sem compreender a luta de classes, pois a ideologia é um dos instrumentos da dominação e, também, uma das formas de luta" (FIGUEIREDO; BRITO; BOTAZZO, 2003, p. 757). É possível, portanto, pensar em um processo de luta em que a saúde se dê de forma horizontal, ou seja, uma representação ampliada de saúde, atrelada não apenas à ausência de doença, mas de bem-estar, acesso aos bens e serviços básicos, à terra, entre outras questões.

\subsection{Ilustrações}

Imagens e ilustrações constituem elementos de linguagem não-verbal fundamentais para a comunicação, em especial para fins didáticos, uma vez que

considera-se que qualquer mensagem visual está diretamente relacionada aos sentidos, ao cérebro, ao corpo, de modo geral, bem como trazem na sua materialidade, na sua composição, os atributos que geram significados, sentidos (DRIGO; SOUZA, 2012, p. 5). 
Assim, as ilustrações se tornam importantes lentes de observação para que o leitor visualize, interprete e teça considerações e comentários sobre o que vê, ou o que representam esses sentidos. A partir da identificação desses elementos, o leitor pode se apropriar de seu conhecimento ou visão de mundo para tirar suas próprias conclusões, que podem ser entendidas de variadas formas, a depender do olhar e do que se deseja ler.

Nos materiais de cunho nacional analisados, foram identificadas 64 ilustrações. Já os materiais da regional Minas Gerais somaram 66 imagens, assim distribuídas:

Quadro 7 - Total de ilustrações nos materiais nacionais.

\begin{tabular}{|c|c|}
\hline $\begin{array}{c}\text { Caderno } \\
\mathrm{n}^{\circ}\end{array}$ & $\begin{array}{c}\text { Total de } \\
\text { Imagens }\end{array}$ \\
\hline 1 & 8 \\
\hline 2 & 0 \\
\hline 4 & 15 \\
\hline 5 & 41 \\
\hline
\end{tabular}

Fonte: Autoria própria.

Quadro 8 - Total de ilustrações nos materiais regionais.

\begin{tabular}{|c|c|}
\hline Material & Total de imagens \\
\hline 2014 & 34 \\
\hline 2018 & 32 \\
\hline
\end{tabular}

Fonte: Autoria Própria.

Todas as ilustrações dos Cadernos do Setor Nacional de Saúde são desenhadas à mão, característica marcante nos materiais de divulgação que trabalham com o conceito de Educação Popular. Já as imagens constantes nas produções regionais dialogam com a tecnologia, visto que, em quase sua totalidade, foram utilizadas fotografias como marcadores de registros das ações desenvolvidas nas oficinas e que deram vida às produções.
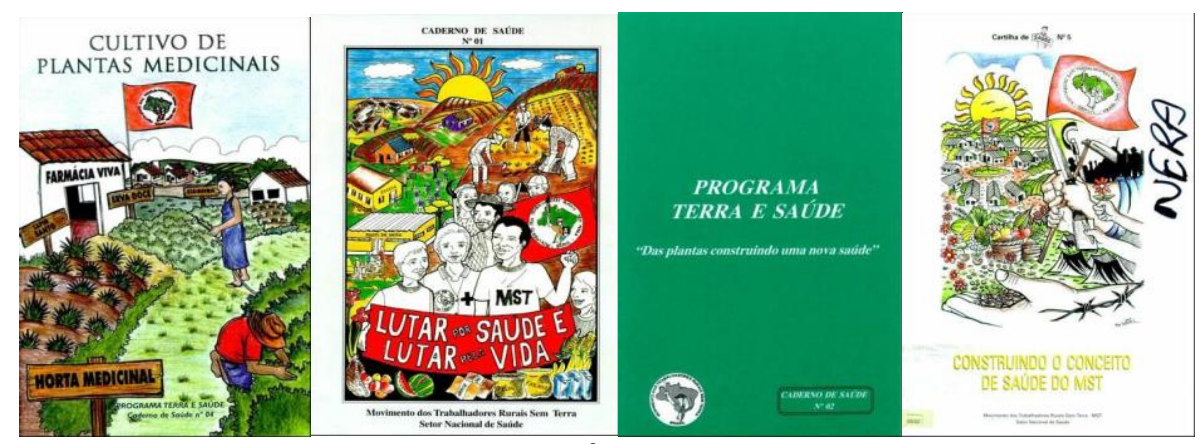

Figura 1: Capas Cadernos de Saúde MST Nacional.

Fonte:

http://www.docvirt.com/docreader.net/DocReader.aspx?bib=BibliotLT\&pagfis=6 457. 


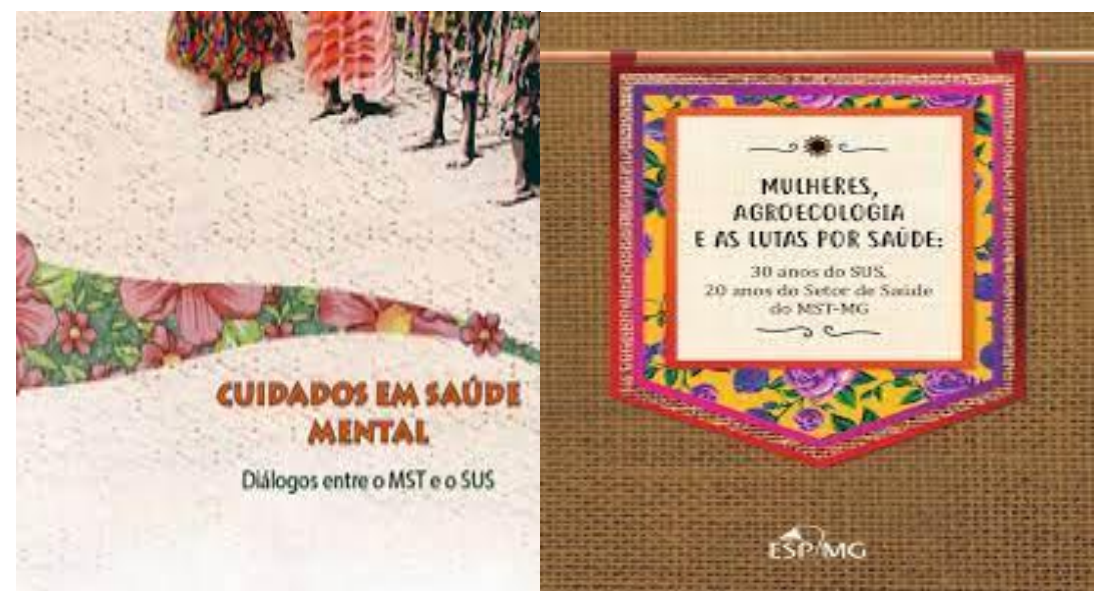

Figura 2: Capas Cadernos de Saúde MST Regional Minas Gerais.

Fonte:

http://www.esp.mg.gov.br/component/search/?all=reposit\%C3\%B3rio\&area= all.

Em relação ao quesito escala, nenhuma ilustração contou com essa dimensão. Quanto às fontes dessas imagens, nos materiais do Setor de Saúde nacional, como se trata de autoria própria com identificação dos artistas na ficha catalográfica (expediente), não se fez menção a essa categoria. Nas produções do Setor de Saúde da regional Minas Gerais, apenas no Caderno de saúde mental foram atribuídos créditos fotográficos à foto de capa. Legendas também não marcaram presença nas ilustrações e fotografias. Araújo (2006) considera que

desenhos são percebidos como um retrato da realidade, equivalem a fotografias no seu valor icônico. Como tal, eles aparecem como momento de um processo; há um antes e um depois que se agregam ao sentido produzido. Da analogia com a fotografia decorre uma exigência de fidelidade e correspondência com o real que determina não só a preferência por estilos de ilustração, mas sobretudo a possibilidade de comunicação (2006, p. 60).

As ilustrações contidas nos Cadernos, como meio de comunicação visual, se dirigem à população do campo de forma compreensível, em uma linguagem que condiz com a realidade do camponês. Assim, são ilustrações que retratam os diálogos entre o sujeito e o mundo que o cerca, e tais figuras são vistas como algo positivo. Nas ilustrações dos Cadernos, os desenhos são figurativos. Para Araújo (2006),

desenhos figurativos, com ambientação a partir de elementos conhecidos, favorecem a interlocução. Aqui assume relevo o tema dos detalhes da figuração. Sendo para os ilustradores apenas um recurso a mais de estilo, para os receptores implicam 'informação': cada detalhe traz uma informação a ser considerada no cômputo final dos sentidos. O volume do úbere de uma vaca indica se ela foi ordenhada ou não; a maneira de segurar uma enxada indica se o agricultor é trabalhador ou relaxado, se já vai embora ou ainda fica; o cercado do chiqueiro informa se o dono tem posses ou é pobre; a posição da sombra indica a hora. Detalhes conhecidos motivam, dão movimento, aumentam credibilidade. Detalhes desconhecidos levam à especulação ou desqualificam a informação. 
Desenhos desambientados, assépticos, não emocionam (ARAÚJO, 2006, p. 60).

Todos esses elementos se configuram nas ilustrações dos materiais. Vejamos, então, as situações e contextos, presentes nos três materiais, que apresentam ilustração como linguagem:

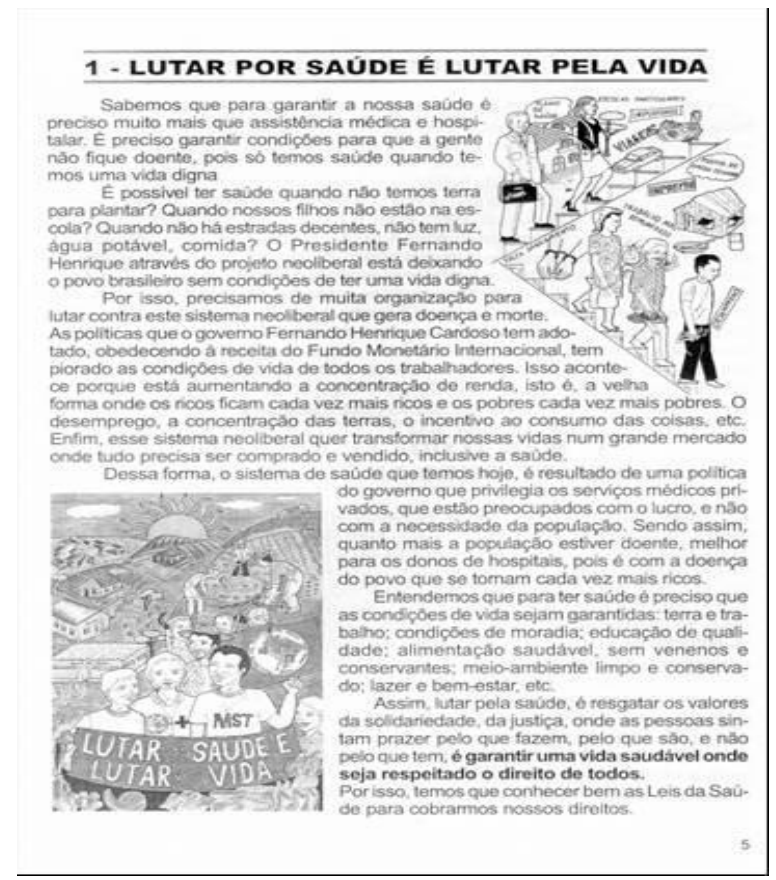

Figura 3: Ilustração Caderno n.0 1.

Fonte:

http://www.docvirt.com/docreader.net/DocReader.aspx?bib=Biblio tLT\&pagfis $=6421$.

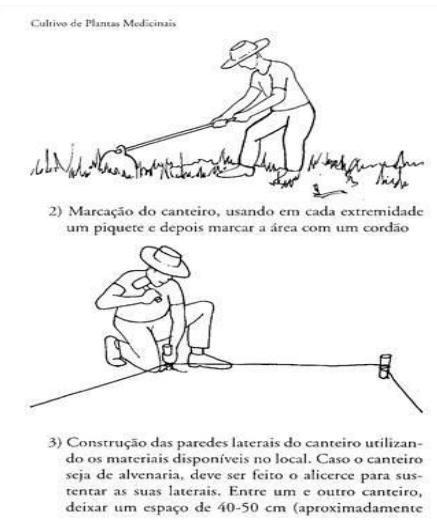

Figura 4: Ilustração Caderno n. 04. Fonte:

http://www.docvirt.com/docreader.net/DocReader.aspx?bib=BibliotLT\&pagfis=6421 


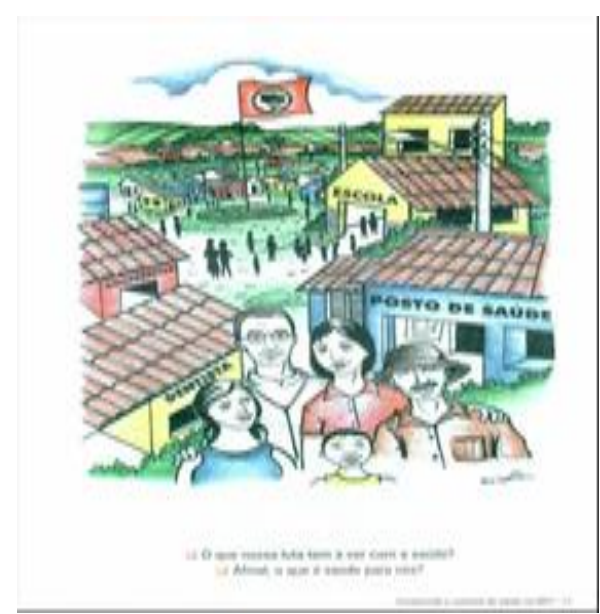

Figura 5: Ilustração Caderno n.0 5.

Fonte:

http://www.docvirt.com/docreader.net/DocReader.aspx?bib $=\mathrm{Bi}$ bliotLT\&pagfis $=6457$

A Figura 3 faz parte do Caderno n. ${ }^{\circ} 1$ - Lutar por saúde é lutar pela vida. Nela, observam-se duas situações: a figura no canto direito aborda o tema da desigualdade social. De um lado, tem-se o meio urbano, local onde o acesso a bens materiais e desejos como uma boa escola, uma saúde digna, sonhos com viagens, entre outros, são vistos como mais acessíveis. Na contramão, tem-se a realidade rural, muitas vezes esquecida, com acesso restrito aos recursos básicos para uma vida digna. É com essa dicotomia que tal ilustração chega aos olhos do trabalhador, afirmando uma desigualdade social que o faz buscar caminhos na luta para uma vida menos desigual.

A Figura 4, presente no Caderno n.0 4 - Cultivo de plantas medicinais, por se tratar da parte técnica do Programa Terra e Saúde - cujo objetivo é apresentar as formas de plantio e uso das plantas medicinais aos companheiros e companheiras do campo -, é quase um manual explicativo de como trabalhar o ambiente para atender às diretrizes do Programa. São imagens claras e objetivas, que facilitam o entendimento do trabalhador, mesmo que este não tenha facilidade com a linguagem verbal.

A Figura 5, que consta no material n. ${ }^{0} 5$, trabalha a imagem para além de uma linguagem visual, uma vez que, em cada ilustração, há uma proposta de interação entre imagem e questionamento. Esse exercício nos parece muito interessante, visto que tal associação permite que o leitor pense na sua realidade e, então, chegue a conclusões que possam despertar o porquê da importância de lutar por saúde em um contexto de sociedade desigual.

\subsection{Gênero}

Como a saúde e a educação, a questão de gênero no MST emerge desde a fundação do Movimento, movida pela necessidade de se construir relações iguais dentro de um espaço coletivo, porque "as mulheres se incorporam nestas ações inicialmente motivadas pela própria necessidade econômica que impulsiona buscarem saídas para garantir a sobrevivência." (ARAÚJO, 2005, p. 26). Denominado inicialmente como Coletivo de Mulheres (1990), passando a 
Coletivo Nacional de Mulheres (2000) e chegando ao Setor de Gênero (2000), essas mulheres se tornaram lideranças na luta pela terra, bem como na permanência no campo. O Setor de Saúde é um dos espaços nos quais a participação das mulheres é maciça, em virtude da capacidade de cuidar para além do zelar, cuidado imbuído de solidariedade e ação política, conforme se destaca na cartilha regional:

Em Minas Gerais, a construção do Setor de Saúde do MST representa a história de luta e participação das mulheres no cuidado à saúde das populações do campo, ao longo de todo período. Inúmeras mulheres estiveram à frente do cuidado à saúde das pessoas em todos os territórios de acampamentos e assentamentos no Estado. (ESP, 2018, p. 21)

Sendo assim, o interesse por essa categoria no presente estudo justificase pelo desejo de compreender quais os papéis ocupados pelas mulheres no desenvolvimento dos Cadernos de saúde; visto que, historicamente, o cuidado sempre esteve ligado à figura feminina, imagem essa que vem sendo paulatinamente desconstruída no interior do Movimento, abrindo espaço para que essas mulheres ocupem novas funções.

Não foi identificada uma categoria que se referisse diretamente às questões de gênero nas produções do Setor Nacional de Saúde. Se considerarmos uma categoria mais ampla, que contemple mulheres e sujeitos LGBT sem-terra, permeados por tabus e preconceitos, parece-nos que tal discussão não se constituía como prioridade no momento da elaboração do material, como é reforçado no trecho abaixo:

Na prática, homens na liderança e nos cabos de enxada nas terras ocupadas; famílias inteiras chegando aos acampamentos. Não tinha escolha, pois a grave crise violentava o direito básico à alimentação e ao trabalho. Acampamentos cheios de vida, e lá estavam elas, as mulheres, e também, mais invisibilizados, os LGBT sem-terra. Combinavam a intensa jornada do trabalho doméstico com a dor, o amor e a tarefa de linha de frente na contenção dos conflitos. Algumas poucas participavam das reuniões, tomavam a palavra com a calça e a blusa larga, que nem sempre eram de suas escolhas, mas sim uma espécie de senha, necessária para serem ouvidas e respeitadas como militantes e não assediadas e desejadas como objeto sexual (MST, 2018, p. 8).

Embora os conteúdos, no interior dos materiais, sejam dirigidos aos companheiros e companheiras, a passagem acima confirma que o processo de reconhecimento das mulheres no contexto da luta pela terra se dá de forma hierárquica e gradual. Como podemos perceber nas produções regionais, a figura da mulher se faz bastante presente e ocupa lugar central no Caderno Mulheres, agroecologia e as lutas por saúde. Os Cadernos n. ${ }^{\circ} 2$ e 4 trataram de aspectos técnicos, sendo que, no Caderno n. ${ }^{\circ} 4$, as ilustrações se dirigem $100 \%$ à figura masculina, o que nos dá margem para concluir que, embora a igualdade de gênero seja pautada, somente os homens estão aptos a plantar a horta, pegar nas enxadas e entender como se faz uma construção de canteiros. À mulher é atribuída a função de aguar o horto e/ou semear mudas. Destarte, essa elaboração advém de um pensamento equivocado, pois a mulher 
camponesa é capaz de ir além daquilo que lhe é condicionado frente ao trabalho no campo. Ela é capaz de articular e mobilizar uma grande rede de saberes em saúde; de organizar atos políticos em celebração do dia 8 de março - Dia Internacional da Mulher -; de transformar desafios em fonte de luta, mesmo em situação de invisibilidade. Conforme aponta Sales:

\begin{abstract}
A presença das mulheres rurais na produção agrícola familiar é um fato. Mesmo na invisibilidade, não se pode negar que elas estão ocupando terras, plantando, colhendo, e cultivando o desejo de ter uma terra livre e usufruí-la com seu trabalho. Presentes na casa, no quintal, na roça e na luta pela terra, as mulheres tiveram ainda de lutar pelo direito de serem reconhecidas como trabalhadoras. A emergência das mulheres rurais nos movimentos sociais proporcionou seu aparecimento como sujeito político, rompendo sua invisibilidade como trabalhadora. Nesse aprendizado e experimentação as mulheres rurais criaram seu próprio movimento, consolidado na década de 1980. Desde então realizam encontros nacionais, marchas e campanhas, criaram coletivos de mulheres e conquistaram direitos (2007, p. 437).
\end{abstract}

Os Cadernos n. 01 e 5 fazem parte de uma mesma discussão acerca do Sistema Único de Saúde, sendo que o de número 5 prioriza a construção do conceito de saúde do próprio Movimento, que vai ao encontro das propostas do SUS. O Caderno de Saúde n. ${ }^{\circ} 5$ traz, aproximadamente, três passagens em que se identifica uma discussão de gênero, contudo, sempre apontando para uma perspectiva coletiva que almeja igualdade para todos. A exemplo:

Fazemos parte de uma organização que está em luta para transformar a sociedade e a situação de injustiça e desigualdade em que vivemos. E falar em igualdade, justiça, participação, é falar de novos valores, onde a relação entre as pessoas, entre homens e mulheres sejam de igualdade, respeito e construção (MST, 2000b, p. 35).

Para além do tratamento superficial da linguagem verbal atribuído ao papel da mulher na saúde, as ilustrações se tornam lacunas para entender em que lugar, de fato, elas se situam ou se situavam no momento de escrita do material. Não todas, mas algumas imagens são passíveis de questionamentos, pois nelas se percebe a típica reprodução de uma sociedade dominada pelo patriarcado. Há um forte indicativo acerca da divisão sexual do trabalho, que Hirata e Kergoat (2007) definem, baseadas na teoria francesa, como:

forma de divisão do trabalho social decorrente das relações sociais entre os sexos; mais do que isso, é um fator prioritário para a sobrevivência da relação social entre os sexos. Essa forma é modulada histórica e socialmente. Tem como características a designação prioritária dos homens à esfera produtiva e das mulheres à esfera reprodutiva e, simultaneamente, a apropriação pelos homens das funções com maior valor social adicionado (políticos, religiosos, militares etc.) (2007, p. 599).

Em um argumento a mais sobre essa temática, Kergoat (2003) alimenta o contraponto ao conceito puro e simples de divisão sexual do trabalho e entoa que 
as condições em que vivem homens e mulheres não são produtos de um destino biológico, mas sobretudo, construções sociais. Homens e mulheres não são uma coleção - ou duas coleções - de indivíduos biologicamente diferentes. Eles formam dois grupos sociais, possuem uma base material, no caso do trabalho entre os sexos, chamada concisamente, divisão sexual do trabalho (2003, p. 1).

Nesse sentido, ao nos depararmos com as imagens ilustrativas do Caderno n. ${ }^{\circ}$, outra lacuna se abre para questionamentos, tais como: em que medida o MST de fato aborda a questão das mulheres no campo da luta? Quais os elementos estruturantes, dentro de uma luta de classe, que se vinculam não somente ao mundo do trabalho? Parece-nos que, ao longo dos anos, tal discussão ganha corpo junto ao crescimento do Setor de Gênero, tendo em vista as imagens e construções contidas em materiais mais recentes, como nos casos do Caderno e da Cartilha regionais de Minas Gerais.

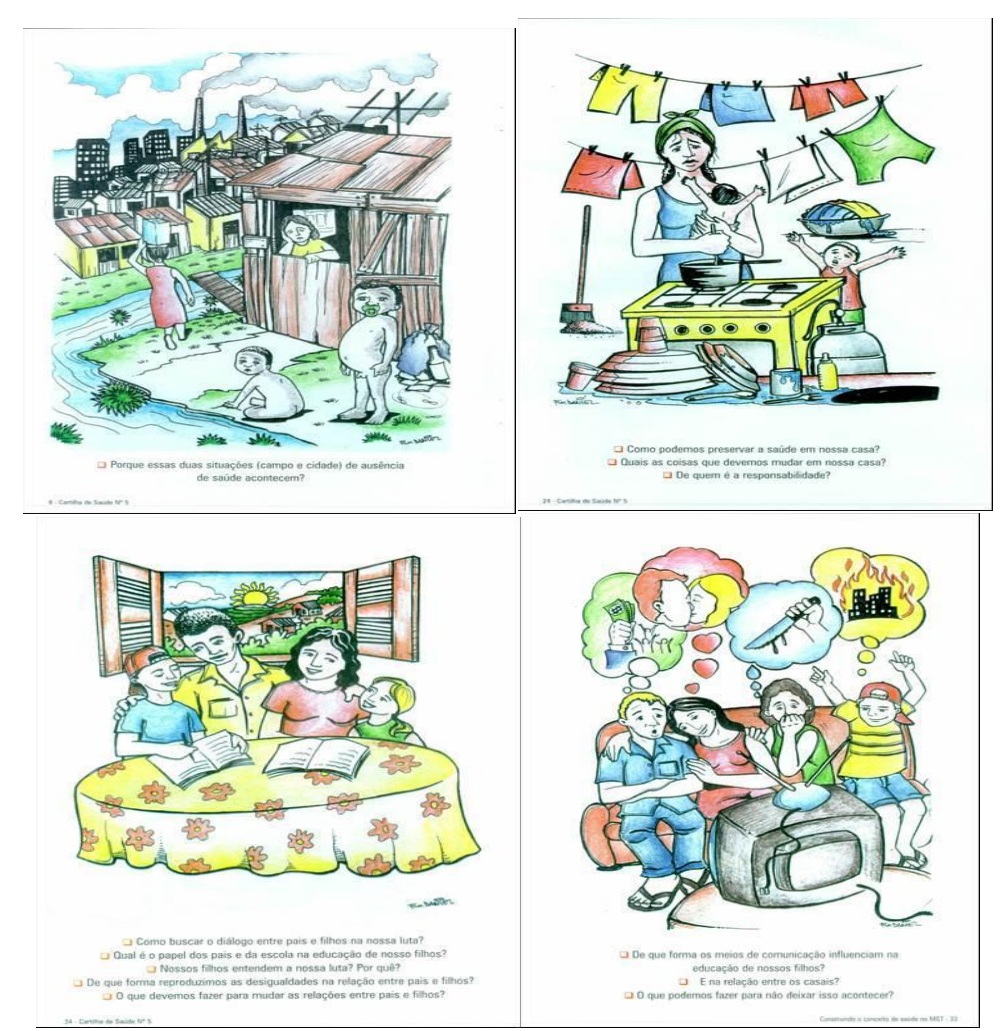

Figuras 5 e 6: Ilustrando gênero no Caderno n. ${ }^{0} 5$.

Fonte:

http://www.docvirt.com/docreader.net/DocReader.aspx?bib=BibliotLT\&pag fis $=6457$.

Ao contrário das imagens acima, os materiais produzidos pelo Setor de Saúde regional, de forma lúdica, interessante e construtiva, colocam a mulher no centro da discussão, considerando-a como atuante na política. Ela cuida, trabalha, vai para o embate, empreende, lidera decisões, participa de oficinas e as realiza, além de também construir a história do Movimento. Toda essa ascensão faz parte de um longo processo de discussão - ainda em construção do fundamental papel que a mulher exerce nos setores do movimento. Durante 
todo o conteúdo desenvolvido na cartilha regional Mulheres, agroecologia e as lutas por saúde, a mulher foi protagonista das suas próprias falas e sentimentos, como se observa no depoimento da assentada Sueli Guimarães Rodrigues:

Eu via as pessoas passando mal dentro do acampamento e com aquela prática de chazinho para os netos fui fazendo os procedimentos (...). O pessoal falava, a Sueli é boa, então sempre tinha gente na minha porta. Aí o coordenador da nossa regional me chamou para entrar. Agora eu sou coordenadora da regional junto com eles, formando a equipe de saúde (ESP, 2018, p. 25).

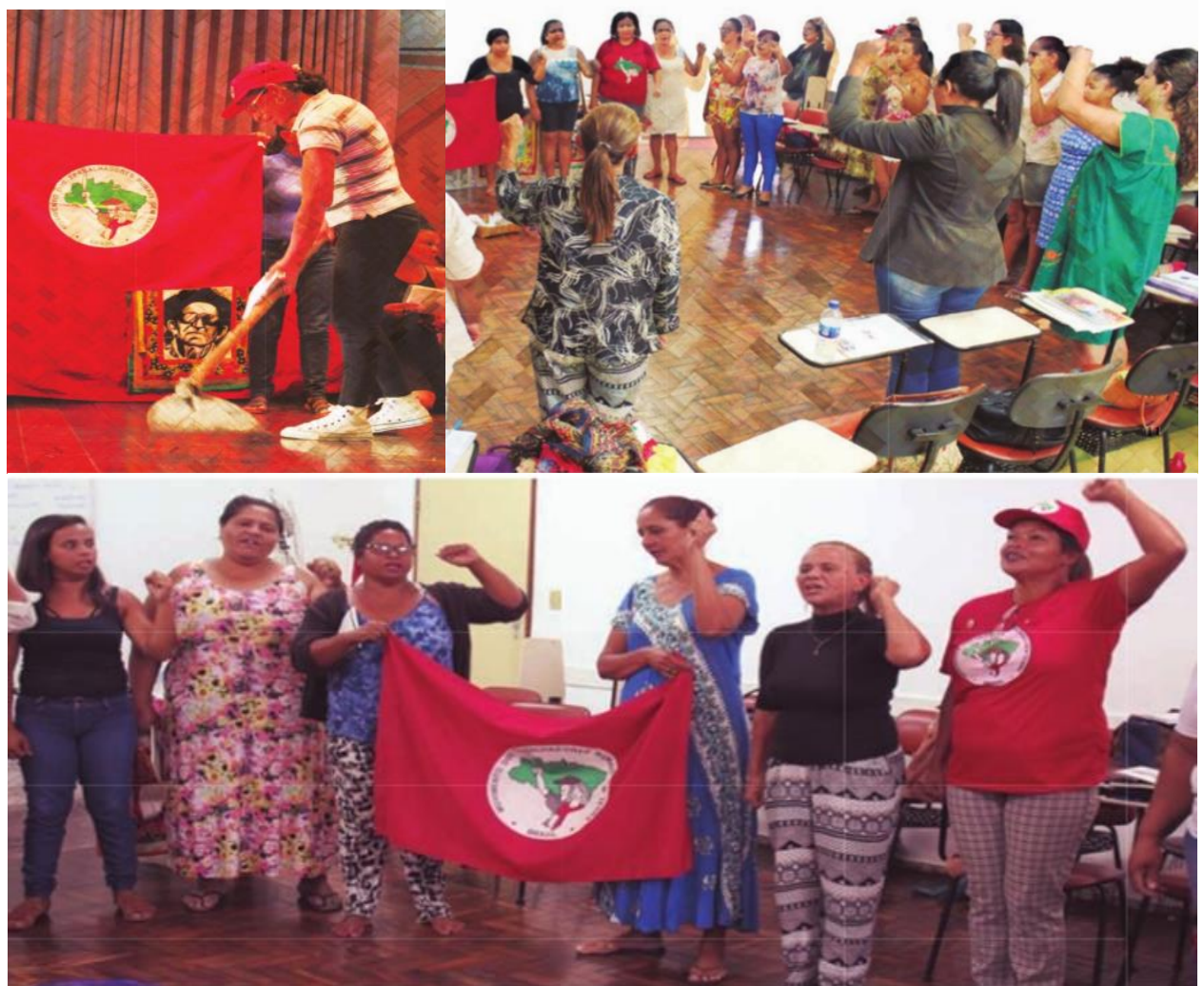

Figuras 7 e 8: Ilustrando Gênero nas produções do Setor de Saúde regional.

Fonte:

https://www.researchgate.net/publication/329782394_Mulheres_Agroecologia_e_ as_Lutas_por_Sau

de_30_anos_do_SUS_20_anos_do_Setor_de_Saude_do_MST.

É importante suscitar que as imagens acima representam mulheres assentadas e acampadas e suas lutas nos diversos espaços que ocupam atualmente. Ainda que as ilustrações agucem interpretações, é válido ressaltar que essas são imagens que, embora transmitam mensagens, precisam ser lidas dentro dos contextos nos quais os eventos se dão. Afinal, como estamos falando de material didático, torna-se imprescindível sempre deixarmos claro que essas são mulheres aparentemente potentes, mas que trazem consigo marcas, individualidades e sonhos, e que a luta por direitos vai além das imagens.

Por fim, no quesito autoria, os Cadernos são construções coletivas dentro do Movimento, priorizando a escrita participativa junto às companheiras e companheiros de todos os estados do país. Nos Cadernos, as autorias estão assim distribuídas: 


\section{Quadro 9: Autoria cadernos de saúde nacional.}

\begin{tabular}{|c|c|c|c|c|}
\hline Caderno & \multicolumn{2}{|c|}{ Autoria } & \multicolumn{2}{c|}{ Ilustração } \\
\hline N. & Mulher & Homem & Mulher & Homem \\
\hline 1 & 4 & 2 & 1 & 0 \\
\hline 2 & 2 & 1 & 0 & 0 \\
\hline 4 & 0 & 2 & 0 & 1 \\
\hline 5 & 13 & 9 & 1 & 1 \\
\hline
\end{tabular}

Fonte: Autoria própria.

Quadro 10: Autoria produção regional.

\begin{tabular}{|c|c|c|c|c|}
\hline Material & \multicolumn{2}{|c|}{ Autoria } & \multicolumn{2}{c|}{ Ilustração } \\
\hline Ano & Mulher & Homem & Mulher & Homem \\
\hline 2014 & 4 & 1 & 3 & 1 \\
\hline 2018 & 11 & 0 & 2 & 0 \\
\hline
\end{tabular}

Fonte: Autoria própria.

Percebe-se uma distribuição da construção do conteúdo de forma justa, com exceção do Caderno n. ${ }^{\circ} 4$, em que os homens são os únicos participantes da sua construção. Nos demais, as mulheres aparecem como principais contribuintes no processo de elaboração dos materiais, atingindo igualdade no quesito ilustração. Por mais que não pareça, são aspectos importantes de se observar, pois passam a ser um indicativo de que a função das mulheres dentro do Setor de Saúde ultrapassa os limites do cuidado, tornando-as também formadoras de opinião.

\section{Considerações finais}

Conforme ressaltado, o MST é um movimento social de luta pela terra e por direitos iguais em uma sociedade desigual. Ao analisarmos tais materiais, foi observada a intensidade com que pautas como direitos, saúde e significado de luta foram abordadas. Evidencia-se, também, uma forte influência da teoria da Educação Popular, visto que a luta por saúde, por educação e por igualdade é a permanente luta contra a opressão, contra o saber e o fazer social hegemônico calcado no sistema capitalista neoliberal.

Do primeiro caderno produzido pelo Setor Nacional de Saúde até os dias de hoje, passaram-se vinte e dois anos. Nesse tempo, a realidade do mundo se transformou. No Brasil, O SUS se consolidou como um dos maiores sistemas de saúde do mundo. As tecnologias sociais para a produção no campo ampliaram os horizontes dos camponeses, os Programas de Educação do Campo oportunizaram aos trabalhadores e trabalhadoras se qualificarem e se formarem como todo cidadão de direito no país.

O Movimento dos Trabalhadores Rurais Sem Terra acompanha, de forma dinâmica, essas mudanças estruturais, seja no modo de informar e formar seus militantes, assentados e acampados; seja propondo políticas públicas como a Política Nacional de Saúde Integral dos Povos do Campo, das Florestas e das Águas, negociando nas esferas do SUS, junto ao Ministério das Saúde; bem 
como as Políticas de Educação no Campo, junto ao Ministério da Educação. Verificou-se que o trabalho de base é ainda a principal forma de inserir o trabalhador rural na luta. É certo que as primeiras produções didáticas nacionais necessitam de um novo olhar, acompanhando essa transformação mundial. Entretanto, os materiais produzidos há 22 anos formaram cidadãos que hoje desfrutam de um conhecimento que fortalece e qualifica a luta.

É imprescindível apontar e reforçar a importância de tais materiais na trajetória do Setor de Saúde, que se tornou uma frente de luta dentro da ação mais ampla e transformadora nos assentamentos e acampamentos do Brasil. A partir de iniciativas como essas, o Setor se aliou a universidades e segmentos educacionais, ampliando o sentido de estar no campo na condição de qualificar os militantes para ações de saúde. Desse modo, são valorizadas as políticas de Educação do Campo, que vão desde a formação técnica até a Pós-graduação, a partir do Programa Nacional de Educação na Reforma Agrária (PRONERA), do Programa de Apoio a Formação Superior em Licenciatura em Educação do Campo (PROCAMPO) e do Programa Nacional de Educação do Campo (PRONACAMPO); políticas diferentes que convergem para o mesmo lugar, ou seja, lutar por saúde é também lutar por conhecimento, por educação e por formação.

Portanto, a edição dos materiais propostos pelo MST, via Setor de Saúde nacional e regional, ao propor o desafio de compilar em páginas suas estratégias de luta pela vida e permanência no campo, bem como seus conhecimentos sobre uma saúde que perpassam pela teoria e pela prática de vivência na terra, demonstram a capacidade e o potencial do Movimento ao construir um conceito genuíno, de que "saúde é lutar contra tudo o que os oprime" (ESP, 2018, p. 9). Isto é, o conceito de saúde perpassa pelo sentido de que, para haver saúde no meio rural, é preciso ter em dia a dignidade humana. É ter comida na mesa de forma sustentável e saudável e ter acesso ao sistema de saúde. É poder exercer seus saberes e práticas tradicionais de saúde sem repressão ou estigma, é reconhecer a questão de gênero não como uma disputa por poder, mas como somatório de forças capazes de transformar a realidade de várias vidas, tendo sempre em mente que a saúde, assim como a educação, não são campos neutros, mas marcados por intensas disputas políticas que só se viabilizam a partir e pela organicidade do Movimento.

Por fim, destacamos que os materiais formativos em saúde produzidos pelo MST elucidam que a saúde e a doença fazem parte da construção social que muda com o tempo e, no caso do Movimento, é uma forma de olhar para o mundo, cumprindo um duplo movimento de garantir os direitos constitucionais em saúde, sem perder de vista os saberes ancestrais e os saberes populares. Observa-se que, dada a dinamicidade do Setor de Saúde e as diferentes demandas regionais, o Setor Nacional tem uma produção mais tímida se comparada às regionais, indicando que as questões de saúde são plurais e diversas e devem ser compreendidas não apenas pelas lentes do macro, mas sobretudo pelas micro experiências.

\section{REFERÊNCIAS}


ALMEIDA, Argus Vasconcelos de; SILVA, Lucélia Santana Torres da; BRITO, Rosanne Lopes de. Desenvolvimento do conteúdo sobre os insetos nos livros didáticos de ciências. Revista Brasileira de Pesquisa em Educação em Ciências, Belo Horizonte, v. 8, n. 1, p. 1-17, 2008.

ARAUJO, Djacira Maria de Oliveira. A Invisibilidade das Mulheres na Memória das Lutas Sociais na América Latina: protagonismo feminino nestas lutas e nos movimentos sociais do campo brasileiro. Ensaio de Pósgraduação: Estudos Latino-Americanos. Faculdade de Serviço Social, Universidade Federal de Juiz de Fora, 2005.

ARAÚJO, Inesita. Materiais educativos e produção dos sentidos na intervenção social. In: MONTEIRO, S.; VARGAS, E. (Org.). Educação, comunicação e tecnologia educacional: interfaces com o campo da saúde. Rio de Janeiro: Editora FIOCRUZ, 2006, p. 49-69. Disponível em: http://books.scielo.org/id/9n7jy/pdf/monteiro-9788575415337-04.pdf. Acesso em: 14 fev. 2021.

ASSIS, Sheila Soares de; PIMENTA, Denise Nacif; SCHALL, Virgínia Torres. A dengue nos livros didáticos de ciências e biologia indicados pelo Programa Nacional do Livro Didático. Revista Ciência \& Educação, Bauru, v. 19, n. 3, p. 633-656, 2013.

BATISTA, Marcus Vinícius de Aragão. CUNHA, Marlécio Maknamara da Silva; CUNHA; CÂNDIDO, Alexandre Luna. Análise do tema virologia em livros didáticos do ensino médio. Ensaio: Pesquisa em educação em ciências, Belo Horizonte, v. 12, n. 1, p. 1-18, 2010.

BRASIL. Guia de livros didáticos: PNLD 2012: apresentação. Brasília, 2011.

BRASIL. Ministério da Educação. Secretaria de Educação Continuada, Alfabetização, Diversidade e Inclusão/SECADI. Diretoria de Políticas de Educação do Campo, Indígena e para as Relações Étnico-Raciais/DPECIRER. Coordenação Geral de Políticas de Educação do Campo/CGPEC. Programa Nacional de Educação no Campo (PRONACAMPO) - Documento Orientador. Brasília: Ministério da Educação, 2013.

BRASIL. Ministério da Saúde. Secretaria de Gestão Estratégica e Participativa. Departamento de Apoio à Gestão Participativa. Caderno de Educação Popular em Saúde. Brasília: Ministério da Saúde. 2007. Disponível em: http://bvsms.saude.gov.br/bvs/publicacoes/caderno_educacao_popular_saude _p1.pdf. Acesso em: 14 fev. 2021.

BRASIL. Secretaria Geral da Presidência da República. Departamento de Participação Social. Departamento de Educação Popular e Mobilização Cidadã. Marco de Referência da Educação Popular para as Políticas Públicas. Brasília: 2014. Disponível em: 
http://www4.planalto.gov.br/consea/publicacoes/outros-assuntos/marco-dereferencia-da-educacao-popular-para-as-politicas-publicas/9-marco-dereferencia-da-educacao-popular-para-as-politicas-publicas.pdf. Acesso em: 14 fev. 2021.

CORSO, Ângela Maria; ALMEIDA, Adriana de. A Educação de jovens e adultos: Aspectos históricos e Sociais. In: XII Congresso Nacional de Educação EDUCERE. Formação de professores, complexidade e trabalho docente. Anais. Curitiba, 2015.

DRIGO, Maria Orgécia; SOUZA, Luciana Pagliarini de. Educação do Olhar: As Representações Visuais em Foco. \#Tear: Revista de Educação e

Tecnologia, Canoas, vol. 1, n.1, 2012.

ESCOLA DE SAÚDE PÚBLICA - ESP (Minas Gerais). Cuidados em Saúde Mental: diálogos entre o MST e o SUS. Belo Horizonte: ESP-MG, 2014.

ESCOLA DE SAÚDE PÚBLICA - ESP (Minas Gerais). Mulheres, agroecologia e as lutas por saúde: 30 anos do SUS, 20 anos do Setor de Saúde do MSTMG. Belo Horizonte: ESP-MG, 2018. Disponível em:

https://www.researchgate.net/publication/329782394_Mulheres_Agroecologia _e_as_Lutas_por_Saude_30_anos_do_SUS_20_anos_do_Setor_de_Saude_do_ MST. Acesso em: 14 jun. 2021.

FERREIRA, Adriano de Melo; SOARES, Cynthia Aparecida Arossa Alves. Aracnídeos peçonhentos: análise das informações nos livros didáticos de ciências. Revista Ciência e Educação, Bauru, v. 14, n. 2, p. 307-314, 2008.

FIGUEIREDO, Gustavo de Oliveira; BRITO, Dyla Tavares de Sá; BOTAZZO, Carlos. Ideologia, fetiche e utopia na saúde: Uma análise a partir da saúde bucal. Ciência e Saúde Coletiva, v. 8, n. 3, p. 753-73, 2003. Disponível em: https://scielosp.org/pdf/csc/2003.v8n3/753-763/pt. Acesso em: 14 jun. 2021.

HIRATA, Helena; KERGOAT, Daniéle. Novas Configurações da divisão sexual do trabalho. Cadernos de Pesquisa, v. 37, n. 132, p. 595-609, Set/Dez. 2007. Disponível em:

https://www.scielo.br/j/cp/a/cCztcWVvvtWGDvFqRmdsBWQ/?lang=pt\&format =pdf $>$ Acesso em: 14 fev. 2021. Acesso em: 14 ago. 2021.

KERGOAT, Danièle. Divisão sexual do trabalho e relações sociais de sexo. Trad. Miriam Nobre, [s.l.] [s.n.], 2003.

LUZ, Zélia Maria Profeta; PIMENTA, Denise Nacif; RABELLO, Ana; SCHALL, Virgínia. Evaluation of informative materials on leishmaniasis distributed in Brazil: criteria and basis the production and improvement of health education materials. Cadernos de Saúde Pública, Rio de Janeiro: v. 19, n. 2, p. 561-569, 2003, Disponível em: 
https://www.scielo.br/scielo.php?script=sci_arttext\&pid=S0102311X2003000200023. 14 ago. 2021.

MOHR, Adriana. Análise do conteúdo de saúde em livros didáticos. Revista Ciência \& Educação, Bauru, v. 6, n. 2, p. 89-106, 2000.

MOVIMENTO DOS TRABALHADORES RURAIS SEM TERRA (MST). Boletim Informativo - Coletivo Nacional de Saúde. [s.I.] [s.n.], Dez. 2007.

MOVIMENTO DOS TRABALHADORES RURAIS SEM TERRA (MST). Caderno de Formação do Setor de Gênero - A conspiração dos gêneros: elementos para o trabalho de base. [s.I.] [s.n.], Jan. 2018.

MOVIMENTO DOS TRABALHADORES RURAIS SEM TERRA (MST). Caderno de Saúde n. ${ }^{1}$ - Lutar por Saúde é lutar pela vida. Osasco: Gráfica e Editora Peres, 1999a. Disponível em:

http://www.docvirt.com/docreader.net/DocReader.aspx?bib=BibliotLT\&pagfis= 6421. 14 ago. 2021.

MOVIMENTO DOS TRABALHADORES RURAIS SEM TERRA (MST). Caderno de Saúde n. ${ }^{\circ} 2$ - Programa Terra e Saúde - Das plantas construindo uma nova saúde. [s.l.] [s.n.], 1999b. Disponível em:

http://www.docvirt.com/docreader.net/DocReader.aspx?bib=BibliotLT\&pagfis= 6421. 14 ago. 2021.

MOVIMENTO DOS TRABALHADORES RURAIS SEM TERRA (MST). Caderno de Saúde n. 04 - Cultivo de Plantas Medicinais. São Paulo: [s.n.], 2000a. Disponível em:

http://www.docvirt.com/docreader.net/DocReader.aspx?bib=BibliotLT\&pagfis= 6421. 12 ago. 2021.

MOVIMENTO DOS TRABALHADORES RURAIS SEM TERRA (MST). Caderno de Saúde n. ${ }^{\circ} 5$ - Construindo o conceito de saúde do MST. [s.l.] [s.n.] 2000b. Disponível em:

https://mst.org.br/download/caderno-de-saude-no-05-construindo-o-conceitode-saude-do-mst/. 12 ago. 2021.

PARO, César Augusto; VENTURA, Miriam; SILVA, Neide Emy Kurokawa. Paulo Freire e o inédito viável: esperança, utopia e transformação na saúde. Revista Trabalho, Educação e Saúde. Rio de Janeiro: v. 18, n. 1, p. 1-22, 2020.

SALES, Celecina de Maria Veras. Mulheres Rurais: Tecendo novas relações e reconhecendo direitos. Estudos Feministas, v. 15, n. 2, Mai/Ago, 2007. Disponível em:

https://www.scielo.br/j/ref/a/zxBLWVLxQwRGT8zgC6fGqdF/?lang=pt\&format= pdf. 12 ago. 2021. 
SANTOS, Juliana Cristina et al. Análise comparativa do conteúdo Filo Mollusca em livro didático e apostilas do ensino médio de cascavel, paraná. Revista Ciência e Educação, Bauru, v. 13, n. 3, p. 311-322, 2007.

SANTOS, Ramofly Bicalho. História da Educação do Campo no Brasil: O protagonismo dos movimentos sociais. Revista Teias, v. 18, n. 51, Out/Dez 2017.

STÊNICO, Joselaine Andréia de Godoy; PAES, Marcela Soares Polato. Paulo Freire e os movimentos sociais: Uma análise da conjuntura brasileira. Revista Educación, v. XXVI, n. 50, p. 47-61, 2017. Disponível em: http://www.scielo.org.pe/pdf/educ/v26n50/a03v26n50.pdf. 12 ago. 2021.

VASCONCELOS, Eymard Mourão. Educação Popular: de uma Prática Alternativa a uma Estratégia de Gestão Participativa das Políticas de Saúde. Revista Saúde Coletiva, Rio de Janeiro, 14(1). p. 67-83, 2004. Disponível em: https://www.ufpb.br/redepopsaude/contents/biblioteca-1/educacao-popularde-uma-pratica-alternativa-a-uma-estrategia-de-gestao-participativa-daspoliticas-de-saude/educacao-popular-e-gestao-participativa.pdf. 12 set. 2021.

VASCONCELOS, Simão Dias; SOUTO, Emanuel. O livro didático de ciências no ensino fundamental - proposta de critérios para análise do conteúdo zoológico. Revista Ciência e Educação, Bauru, v. 9, n. 1, p. 93-104, 2003.

Recebido em: 10 de julho de 2021.

Aceito em: 19 de agosto de 2021. Publicado em: 15 de dezembro de 2021. 